\title{
Loot Boxes: Gambling-Like Mechanics in Video Games
}

\author{
Leon Y. Xiao ${ }^{1,2,3,}$, Laura L. Henderson ${ }^{1}$, Rune K. L. Nielsen ${ }^{4}$, Paweł Grabarczyk ${ }^{4}$, \\ Philip W.S. Newall ${ }^{5}$ \\ ${ }^{1}$ The Honourable Society of Lincoln's Inn, Lincoln's Inn, London WC2A 3TL, United \\ Kingdom \\ ${ }^{2}$ School of Law, Queen Mary University of London, Mile End Road, London E1 4NS, \\ United Kingdom \\ ${ }^{3}$ The City Law School, City, University of London, Northampton Square, Clerkenwell, \\ London EC1V 0HB, United Kingdom \\ ${ }^{4}$ IT University of Copenhagen, Rued Langgaards Vej 7, 2300 København, Denmark \\ ${ }^{5}$ Experimental Gambling Research Laboratory, School of Health, Medical and Applied \\ Sciences, CQUniversity, 400 Kent St, Sydney, NSW 2000, Australia \\ leon.xiao.y@gmail.com \\ *Corresponding author
}

\section{Synonyms}

Loot Crates; Prize Crates; Booster Packs; Gachas; Gatchas; Virtual Gashapons; Blind Boxes; Blind Bags; Random Reward Mechanisms; Randomised Monetisation Methods; Surprise Mechanics

\section{Definition}

Loot boxes are mechanics often found in video games that provide the player with randomised virtual rewards. Some loot boxes can be paid for with real-world money and therefore share structural and psychological similarities with gambling.

\section{Introduction}

'Loot boxes' is a colloquial catch-all terminology used to describe software features, typically found in video games, that provide the player with randomised virtual rewards [1]. The player must satisfy an 'eligibility condition' to engage with (or 'open') the loot box: this could be by defeating a certain in-game enemy, by obtaining a certain virtual item, by watching embedded commercials, or (more importantly) through purchasing using fiat currency (or real-world money) [2]. Once the player engages with the loot box, a 'random procedure,' of potentially varying degrees of complexity [3], is used to determine what virtual rewards the player will obtain. The virtual 'rewards' that the player obtains may be merely cosmetic items that, e.g., change the colour of the player's armour, or may, alternatively, influence gameplay more significantly by, e.g., unlocking additional game content or increasing the player's in-game power [4]. These 'rewards' may be transferable (or 'sold') to other players in exchange for real-world money [5], or may be restricted by the video game company for use only inside the in-game economy by the original player who engaged with the loot box [6]. The act of engaging 
with a loot box may be represented in-game as the player literally opening a box containing loot; however, the loot box mechanic can also be visually represented in other forms, e.g., as tearing open a card pack, spinning a prize wheel, or receiving a capsule from a 'gacha' vending machine. Regardless of their visual representation, all loot boxes share the structural characteristics of being triggered by satisfying an 'eligibility condition;' involve a 'random procedure;' and provide 'rewards,' as described above.

Nielsen and Grabarczyk (2019) proposed a framework for classifying various implementations of loot boxes into four categories which focuses on whether the 'eligibility condition' requires spending real-world money to satisfy, and whether the 'rewards' can be transferred to other players in exchange for legal tender and therefore possesses real-world value, as shown in Table 1.

\begin{tabular}{|c|c|c|}
\hline Category & Description & Regulatory Positions \\
\hline Embedded-Embedded & $\begin{array}{l}\text { Costs real-world money to engage and } \\
\text { its reward does have real-world value. }\end{array}$ & $\begin{array}{l}\text { Regulated as gambling in } \\
\text { Belgium [7], the Netherlands } \\
\text { [8], the UK [9] and most other } \\
\text { countries that regulate } \\
\text { gambling as a licensable } \\
\text { activity. } \\
\text { Banned as gambling in most } \\
\text { countries that more heavily } \\
\text { prohibit gambling. }\end{array}$ \\
\hline Embedded-Isolated & $\begin{array}{l}\text { Costs real-world money to engage but } \\
\text { its reward does not have real-world value. }\end{array}$ & $\begin{array}{l}\text { Regulated as gambling in } \\
\text { Belgium [7]. } \\
\text { Unregulated in most other } \\
\text { countries. }\end{array}$ \\
\hline Isolated-Embedded & $\begin{array}{l}\text { Does not cost real-world money to engage but } \\
\text { its reward does have real-world value. }\end{array}$ & Unregulated in most countries. \\
\hline Isolated-Isolated & $\begin{array}{l}\text { Does not cost real-world money to engage and } \\
\text { its reward does not have real-world value. }\end{array}$ & Unregulated in most countries. \\
\hline
\end{tabular}

Table 1. Four categories of loot boxes proposed by Nielsen and Grabarczyk (2019).

\section{Paid Loot Boxes in Context}

Loot boxes that players have to purchase with real-world money to engage with are implemented by companies as monetisation methods in video games, known as 'microtransactions,' which represent an alternative, or complementary, business model to selling copies of the software or providing subscription-based services [10]. Analysis of loot box spending data has revealed that the loot boxes of one single game (Counter-Strike: Global Offensive) generated US\$528,000 in one day in one country alone, thus hinting at the immense size of the global loot box market [11].

In terms of the historical context and development of loot boxes, it has been suggested that using loot boxes to monetise video games was inspired by how collectible sports cards and fantasy trading cards (e.g., Magic: The Gathering) are sold in blind, randomised packs in 
order to encourage players to buy more packs and increase revenue $[2,4,12]$. These randomised packs were designed to contain rare cards, known as 'chase cards,' that were less likely to be included in packs than other cards, and were therefore more sought-after and monetarily valuable. The consumer was thereby encouraged to purchase more packs in order to obtain such rare 'chase cards,' but they would more often only obtain less valuable, duplicate cards that they already possessed when they try to 'chase' rare cards.

Loot boxes are implemented in highly popular home console games, e.g., the Ultimate Team Packs in Electronic Art's FIFA games [13]. Presently, loot boxes are prevalent in video games, particularly on mobile platforms, e.g., Android and iOS: in 2019, 59\% of the highestgrossing iPhone games in the UK contained loot boxes, whilst $36 \%$ of the 50 Highest grossing PC games on Steam contained loot boxes [14]. Compared to in the UK, which represents the Western video game market, loot boxes are significantly more prevalent in China: in 2020, 91\% of the 100 highest-grossing iPhone games contained loot boxes [15]. This reflects that video game markets in different countries may implement loot boxes to different degrees. Video games containing loot boxes are also generally given low age ratings: $95 \%$ of the highest-grossing iPhone games containing loot boxes were deemed suitable for children aged 12+ [14]. This suggests that children are regularly exposed to loot boxes and can readily purchase them. The UK Gambling Commission's survey [16] found that $23 \%$ of 11 to 16-year-olds reported paying real-world money for loot boxes.

\section{Potential Harms: Links with Problem Gambling}

Paid loot boxes, because of the fact that players spend real-world money to engage with them and because of their randomised nature, are structurally and psychologically similar to gambling [1]. This encompasses Embedded-Embedded and Embedded-Isolated loot boxes under Nielsen and Grabarczyk's categorisation (2019). Further, loot box purchasing has been found to be positively correlated with problem gambling severity in more than a dozen empirical studies in Western countries [17], e.g., the US [18], Australasia [19], Denmark [20] and Germany [21]. Players with higher problem gambling severity tend to spend more money purchasing loot boxes [22]. In Western countries loot box spending appears to be more strongly correlated with relatively 'gamified' gambling games, e.g., online slot machines, and not correlated with more traditional gambling formats, e.g., playing bingo or the lottery in person [23]. The relationship between loot boxes and gambling may be weaker in nonWestern countries where gambling is more heavily prohibited, rather than regulated as a licensable activity, e.g., China, where lottery products represent the only legally available commercial gambling opportunity [24]. Cultural differences and legal differences in gambling product availability may affect the relationship between loot boxes and gambling, and remains a direction for future research.

Further, as in gambling contexts $[25,26]$, the vast majority of loot box revenue is generated by a small minority of players spending significant amounts of money [11]. This small minority of players have been identified as generally being players with problem gambling issues, rather than players with high personal incomes, thus suggesting that video game companies may be disproportionally profiting from potentially vulnerable consumers [27]. 
Researchers have also suggested that cognitive biases that are present in gambling contexts, e.g., the gambler's fallacy and loss chasing, which lead to maladaptive gambling, may also apply to loot box purchasing behaviour and lead to maladaptive loot box overspending [2, 4, 28]. Finally, it has yet to be determined whether engagement with loot boxes in childhood affects a person's risk of developing gambling problems later in life.

\section{Regulation by Law and Industry Self-Regulation}

Paid loot boxes have been the subject of regulatory scrutiny by gambling regulators and policymakers in many countries because of their similarities with gambling and because of the link between loot box purchasing and problem gambling severity [29]. In particular, concerns about children engaging with loot boxes have been raised because they may be more susceptible to overspending money and more in need of consumer protection measures [30, 31]. Different jurisdictions are regulating the various categories of loot boxes to varying extents [4], as shown in Table 1. Applying existing gambling law has been how loot boxes have become regulated in nearly all countries: various countries diverge as to which of the two categories of paid loot boxes (i.e., Embedded-Embedded and Embedded-Isolated loot boxes as defined by Nielsen and Grabarczyk) constitute gambling and are therefore regulated: nearly all countries agree that Embedded-Embedded constitute gambling, but only a small minority of countries (e.g., Belgium) have taken the position that Embedded-Isolated loot boxes also constitute gambling. It is rather paradoxical that randomised physical sports and trading card packs, which arguably inspired loot boxes, are generally not considered to be a form of gambling and have thereby evaded regulatory scrutiny. Such physical packs legally constitute gambling in most countries because: they are bought with real-world money; their content is randomised; and the content has real-world monetary value because it can be sold to other people. Future research should consider why such physical EmbeddedEmbedded loot boxes are not considered to be gambling [32].

The simplest regulatory solution is to ban the sale of loot boxes. This has effectively been done in Belgium where all paid loot boxes have been determined to be gambling and where no gambling licences have been granted to video game companies for the sale of loot boxes [7]. This prevents Belgian players from purchasing loot boxes and thus shields them from potential harms. However, this ban in Belgium has led to the removal of many video games that rely on loot boxes to generate revenue and which can no longer be profitably operated in that country [4]. A blanket ban does not offer players freedom to play the video games they want or to engage with loot boxes, and negatively affects video game companies' commercial interests. Conversely, non-regulation would continue to expose players, including vulnerable consumers, to potential loot box harms, and is arguably inadequate and unsatisfactory because of the precautionary principle of public health [33], which states that the lack of scientific certainty cannot justify regulatory inaction in a situation of high potential risk. Middle ground approaches that lie between a blanket ban and non-regulation have also been proposed and adopted in certain countries: e.g., restricting loot box purchasing only when a player attempts to go above a certain maximum spending limit $[34,35,4]$. 
Other consumer protection measures, which have been applied in gambling contexts [36], have also been identified as being potentially applicable to loot boxes $[37,38]$. The most prominent non-restrictive regulatory measure is the disclosure of 'winning' probabilities, which reveals how likely a player is to obtain a particular reward, as implemented in Mario Kart Tour (2019). This would require video game companies to reveal and publish the exact probabilities of obtaining each randomised loot box reward. The video game industry has increasingly imposed this requirement as self-regulation, e.g., by Apple [39], Google [40], and the major hardware providers and game publishers [41]. This measure has also been adopted as law in China (presently the only country to do so), which has led to widespread compliance; however, the prominence and accessibility of disclosure have been identified as being suboptimal [15]. A survey of Chinese video game players found that $85 \%$ of loot box purchasers reported seeing probability disclosures (meaning that they have been reasonably widely seen by players); however, only $19 \%$ of this group reported spending less money on loot boxes as a result of seeing the disclosures [24]. This suggests that loot box probability disclosures may be of limited effectiveness at reducing loot box spending even if they are accessibly and prominently displayed such that all players can see them [42]. The video game industry has been widely supportive of loot box probability disclosure as an industry selfregulatory measure aimed at ensuring consumer protection [41], but whether self-regulation is effective remains to be assessed by future research.

Loot boxes and gambling may share many structural similarities; however, they are dissimilar in at least one regard: how the company makes money. Gambling operators lose money when the player wins money, which is why gambling operators must ensure that the gambling games are designed such that the operator is more likely than the player to win. In contrast, a video game company does not directly lose money when the player wins a reward, valuable or otherwise, as it does not directly cost money to give players these virtual rewards.

However, it should also be noted that a video game company would face an indirect loss when a player wins a valuable reward [43]. A player may stop purchasing a loot box after receiving their desired reward, meaning that the video game company may stop making money from that player after the valuable reward is given out. In order to be sustainable, many loot box systems rely on frequent updates with new rewards, but each new reward costs money for the video game company to develop, meaning that companies would have to expend more costs to develop more new content if players are able to more easily obtain desirable rewards. Further, the value and desirability of a reward would decrease if all players managed to obtain it: it would no longer be a 'rare' reward with which players could impress others. However, despite the potential for indirect loss, video game companies are still financially able to give out their most valuable rewards more frequently than traditional gambling operators. This means that loot box consumer protection methods do not have to be limited to what has been done in gambling contexts, and that loot box consumers could be additionally protected by novel features of ethical game design, e.g., allowing players to win valuable rewards more often $[37,38,42]$. 


\section{Conclusion: Directions for Future Research}

Loot boxes, and paid loot boxes in particular, represent a relatively novel mechanic in video games. Despite increasing research attention being paid to the issue, further research is required to fill in the existing knowledge gaps. Future correlational research between loot boxes and gambling should examine whether loot box purchasing is more strongly correlated with engagement with specific gambling products, rather than engagement with gambling in general. Existing research has largely utilised self-reported data: transparent collaboration with the video game industry may provide more reliable data. Indeed, qualitative methods may assist in better understanding individual players' experiences with loot boxes [44], and gauging players' views as to the implementation and regulation of loot boxes [45]: this is especially relevant for Embedded-Isolated loot boxes because, although this category represents the vast majority of paid loot boxes implemented in video games, these mechanics have no obvious counterparts in non-digital contexts and therefore there is not translatable literature from other fields. Further, cross-cultural perspectives would clarify whether players in various countries are experiencing loot boxes differently. Additionally, neuroscience perspectives may shed light on how player's cognition is affected when engaging with loot boxes: such perspectives are prominent in research on gambling disorder; however, as of yet, they are missing from the loot box literature. Finally, the prevalence of serious problems with loot box spending has never been assessed, and it is not known whether such problems are caused by exposure to loot boxes or are instead symptoms of pre-existing underlying issues. In conclusion, despite recent advances made by the literature, loot boxes remain an area deserving of further research.

\section{References}

1. Drummond, A., Sauer, J.D.: Video Game Loot Boxes Are Psychologically Akin to Gambling. Nat. Hum. Behav. 2, 530 532 (2018). https://doi.org/10.1038/s41562-018-0360-1.

2. Nielsen, R.K.L., Grabarczyk, P.: Are Loot Boxes Gambling? Random Reward Mechanisms in Video Games. ToDIGRA. 4, 171-207 (2019). https://doi.org/10.26503/todigra.v4i3.104.

3. Ballou, N., Gbadamosi, C.T.T., Zendle, D.: The hidden intricacy of loot box design: A granular description of random monetized reward features, https://doi.org/10.31234/osf.io/xeckb, (2020). https://doi.org/10.31234/osf.io/xeckb.

4. Xiao, L.Y.: Regulating Loot Boxes as Gambling? Towards a Combined Legal and Self-Regulatory Consumer Protection Approach. Interactive Entertainment Law Rev. 4, 27-47 (2021). https://doi.org/10.4337/ielr.2021.01.02.

5. Drummond, A., Sauer, J.D., Hall, L.C., Zendle, D., Loudon, M.R.: Why loot boxes could be regulated as gambling. Nature Human Behaviour. 4, 986 (2020). https://doi.org/10.1038/s41562-020-0900-3.

6. Xiao, L.Y.: Which Implementations of Loot Boxes Constitute Gambling? A UK Legal Perspective on the Potential Harms of Random Reward Mechanisms. International Journal of Mental Health and Addiction. Advance Online Publication, (2020). https://doi.org/10.1007/s11469-020-00372-3.

7. Belgische Kansspelcommissie [Belgian Gaming Commission]: Onderzoeksrapport loot boxen [Research Report on Loot Boxes]. (2018).

8. Kansspelautoriteit [The Netherlands Gambling Authority]: Onderzoek naar loot boxes: Een buit of een last? [Study into Loot Boxes: A Treasure or a Burden?]. (2018).

9. UK Gambling Commission: Virtual Currencies, eSports and Social Gaming — Position Paper. (2017).

10. Petrovskaya, E., Zendle, D.: The Battle Pass: a Mixed-Methods Investigation into a Growing Type of Video Game Monetisation. (2020). https://doi.org/10.31219/osf.io/vnmeq.

11. Zendle, D., Petrovskaya, E., Wardle, H.: How do loot boxes make money? An analysis of a very large dataset of real Chinese CSGO loot box openings. (2020). https://doi.org/10.31234/osf.io/5k2sy.

12. Švelch, J.: Mediatization of a card game: Magic: The Gathering, esports, and streaming. Media, Culture \& Society. 42 , 838-856 (2020). https://doi.org/10.1177/0163443719876536. 
13. Electronic Arts: Pack Probability in FIFA Ultimate Team, https://www.ea.com/games/fifa/news/fifa-pack-probabilities, last accessed 2021/04/08.

14. Zendle, D., Meyer, R., Cairns, P., Waters, S., Ballou, N.: The prevalence of loot boxes in mobile and desktop games. Addiction. 115, 1768-1772 (2020). https://doi.org/10.1111/add.14973.

15. Xiao, L.Y., Henderson, L.L., Yang, Y., Newall, P.W.S.: Gaming the system: suboptimal compliance with loot box probability disclosure regulations in China. Behavioural Public Policy. Advance Online Publication, 1-27 (2021). https://doi.org/10.1017/bpp.2021.23.

16. UK Gambling Commission: Young People and Gambling Survey 2019: A research study among 11-16 year olds in Great Britain. (2019).

17. Garea, S.S., Drummond, A., Sauer, J.D., Hall, L.C., Williams, M.N.: Meta-analysis of the relationship between problem gambling, excessive gaming and loot box spending. International Gambling Studies. Advance Online Publication, 1-20 (2021). https://doi.org/10.1080/14459795.2021.1914705.

18. Zendle, D., Cairns, P.: Loot boxes are again linked to problem gambling: Results of a replication study. PLoS One 14(3): e0213194. 14, (2019). https://doi.org/10.1371/journal.pone.0213194.

19. Drummond, A., Sauer, J.D., Ferguson, C.J., Hall, L.C.: The relationship between problem gambling, excessive gaming, psychological distress and spending on loot boxes in Aotearoa New Zealand, Australia, and the United States-A crossnational survey. PLOS ONE. 15, e0230378 (2020). https://doi.org/10.1371/journal.pone.0230378.

20. Kristiansen, S., Severin, M.C.: Loot box engagement and problem gambling among adolescent gamers: Findings from a national survey. Addict. Behav. 103, 106254 (2019). https://doi.org/10.1016/j.addbeh.2019.106254.

21. von Meduna, M., Steinmetz, F., Ante, L., Reynolds, J., Fiedler, I.: Loot boxes are gambling-like elements in video games with harmful potential: Results from a large-scale population survey. Technology in Society. 63, 101395 (2020). https://doi.org/10.1016/j.techsoc.2020.101395.

22. Zendle, D., Cairns, P.: Video game loot boxes are linked to problem gambling: Results of a large-scale survey. PLoS One 13(11): e0206767. 13, (2018). https://doi.org/10.1371/journal.pone.0206767.

23. Zendle, D.: Beyond loot boxes: a variety of gambling-like practices in video games are linked to both problem gambling and disordered gaming. PeerJ. 8, e9466 (2020). https://doi.org/10.7717/peerj.9466.

24. Xiao, L.Y., Fraser, T.C., Newall, P.W.S.: Opening Pandora's loot box: Novel links with gambling, and player opinions on probability disclosures and pity-timers in China, https://psyarxiv.com/837dv/, (2021). https://doi.org/10.31234/osf.io/837dv.

25. Deng, X., Lesch, T., Clark, L.: Pareto distributions in online casino gambling: Sensitivity to timeframe and associations with self exclusion. Addictive Behaviors. 120, 106968 (2021). https://doi.org/10.1016/j.addbeh.2021.106968.

26. Muggleton, N., Parpart, P., Newall, P., Leake, D., Gathergood, J., Stewart, N.: The association between gambling and financial, social and health outcomes in big financial data. Nature Human Behaviour. 5, 319-326 (2021). https://doi.org/10.1038/s41562-020-01045-w.

27. Close, J., Spicer, S.G., Nicklin, L.L., Uther, M., Lloyd, J., Lloyd, H.: Secondary analysis of loot box data: Are highspending "whales" wealthy gamers or problem gamblers? Addictive Behaviors. 117, 106851 (2021). https://doi.org/10.1016/j.addbeh.2021.106851.

28. King, D.L., Delfabbro, P.H.: Predatory Monetization Schemes in Video Games (e.g. 'Loot Boxes') and Internet Gaming Disorder. Addiction. 113, 1967-1969 (2018). https://doi.org/10.1111/add.14286.

29. Cerulli-Harms, A., Münsch, M., Thorun, C., Michaelsen, F., Hausemer, P.: Loot boxes in online games and their effect on consumers, in particular young consumers. Policy Department for Economic, Scientific and Quality of Life Policies (EU) (2020).

30. Wardle, H., Zendle, D.: Loot Boxes, Gambling, and Problem Gambling Among Young People: Results from a CrossSectional Online Survey. Cyberpsychology, Behavior, and Social Networking. 24, 267-274 (2021). https://doi.org/10.1089/cyber.2020.0299.

31. Zendle, D., Meyer, R., Over, H.: Adolescents and loot boxes: links with problem gambling and motivations for purchase. R. Soc. open sci 6: 190049. 6, 190049 (2019). https://doi.org/10.1098/rsos.190049.

32. Zendle, D., Walasek, L., Cairns, P., Meyer, R., Drummond, A.: Links between problem gambling and spending on booster packs in collectible card games: A conceptual replication of research on loot boxes. PLOS ONE. 16, e0247855 (2021). https://doi.org/10.1371/journal.pone.0247855.

33. Digital, Culture, Media and Sport Committee of the House of Commons (UK): Immersive and Addictive Technologies: Fifteenth Report of Session 2017-19. (2019).

34. Drummond, A., Sauer, J.D., Hall, L.C.: Loot Box Limit-setting: a Potential Policy to Protect Video Game Users With Gambling Problems? Addiction. 114, 935-936 (2019). https://doi.org/10.1111/add.14583.

35. Xiao, L.Y.: People's Republic of China Legal Update: The Notice on the Prevention of Online Gaming Addiction in Juveniles (Published October 25, 2019, Effective November 1, 2019). Gaming Law Rev. 24, 51-53 (2020). https://doi.org/10.1089/glr2.2019.0002. 
36. Livingstone, C., Rintoul, A., Lacy-Vawdon, C. de, Borland, R., Dietze, P., Jenkinson, R., Livingston, M., Room, R., Smith, B., Stoove, M., Winter, R., Hill, P.: Identifying effective policy interventions to prevent gambling-related harm. Victorian Responsible Gambling Foundation, Melbourne, Australia (2019).

37. King, D.L., Delfabbro, P.H.: Video Game Monetization (e.g., 'Loot Boxes'): a Blueprint for Practical Social Responsibility Measures. Int. J. Ment. Health Addiction. 17, 166-179 (2019). https://doi.org/10.1007/s11469-018-00093.

38. Xiao, L.Y., Henderson, L.L.: Towards an Ethical Game Design Solution to Loot Boxes: a Commentary on King and Delfabbro. Int J Ment Health Addiction. 19, 177-192 (2021). https://doi.org/10.1007/s11469-019-00164-4.

39. Kuchera, B.: Apple adds new rules for loot boxes, requires disclosure of probabilities, https://web.archive.org/web/20200821095535/https:/www.polygon.com/2017/12/21/16805392/loot-box-odds-rulesapple-app-store, last accessed 2020/08/21.

40. Gach, E.: Google Now Requires App Makers to Disclose Loot Box Odds, kotaku.com/google-now-requires-app-makersto-disclose-loot-box-odd-1835134642, last accessed 2019/08/25.

41. Entertainment Software Association (ESA): Video Game Industry Commitments to Further Inform Consumer Purchases, https://www.theesa.com/perspectives/video-game-industry-commitments-to-further-inform-consumer-purchases/, last accessed 2021/03/12.

42. Xiao, L.Y., Newall, P.W.S.: Probability disclosures are not enough: Reducing loot box reward complexity as a part of ethical video game design, https://psyarxiv.com/nuksd/, (2021). https://doi.org/10.31234/osf.io/nuksd.

43. Xiao, L.Y.: Conceptualising the Loot Box Transaction as a Gamble Between the Purchasing Player and the Video Game Company. International Journal of Mental Health and Addiction. Advance online publication., (2020). https://doi.org/10.1007/s11469-020-00328-7.

44. Nicklin, L.L., Spicer, S.G., Close, J., Parke, J., Smith, O., Raymen, T., Lloyd, H., Lloyd, J.: “It's the Attraction of Winning that Draws You in"-A Qualitative Investigation of Reasons and Facilitators for Videogame Loot Box Engagement in UK Gamers. Journal of Clinical Medicine. 10, 2103 (2021). https://doi.org/10.3390/jcm10102103.

45. Petrovskaya, E., Zendle, D.: Predatory monetisation? A categorisation of unfair, misleading, and aggressive monetisation techniques in digital games from the perspective of players, https://psyarxiv.com/cdwhq/, (2021). https://doi.org/10.31234/osf.io/cdwhq. 